\title{
Badminton Teaching Present Situation and Development Countermeasures in Shanghai College
}

\author{
Zhou Ruizhang \\ College of Higher Technical, \\ Shanghai Maritime University, Shanghai, 200136 \\ E-mail: 448716587 @qq.com
}

\begin{abstract}
Badminton is an extremely attractive and influential sport which enjoys a high reputation in the world. This paper designs questionnaires based on Shanghai college badminton teaching at present, and analyzes the survey results as well as puts forward to the countermeasures and suggestions, with the hope of providing references and help to college badminton courses in the future.
\end{abstract}

Keywords- Shanghai, College, Badminton, Teaching

\section{RESEARCH OBJECT AND METHOD}

\section{A. Research Object}

According to the research need, this paper took 10 colleges from the total 66 Shanghai colleges offering badminton teaching as sample to do the survey and analyses, hoping the selected samples have bigger coverage and more representative, thus reflects the development level of badminton teaching standards of Shanghai colleges. It took the students and teachers of the following 10 colleges as sample: Shanghai University, Shanghai University of Sport, Shanghai Normal University, Shanghai Ocean University, Shanghai Maritime University, Shanghai Finance University, Shanghai University of Finance and Economics, Fudan University, Tongji University, Shanghai Jiaotong University.

\section{B. Research Method}

\section{1) Documentation Method}

Through extensive reading of P.E and Education Science of sports schools, a large number of badminton data both at home and abroad as well as the related books and document literature of P.E teaching reform and course resource development, looking up to dozes of books related to badminton courses from national P.E journals, retrieving more than 40 papers at home and abroad through China Journal Net, it fully understood the preface trends and research status of China college badminton teaching and laid the theory foundation of this paper.

2) Questionnaire Method

a) Questionnaire Design. Based on basic the requirement of sociology regarding the design of questionnaire, it takes the document literature as reference and makes analysis, primarily determines the related factors and draws up the expert survey ,sorts out the factors with high expert confirmation rate to form questionnaire draft. After several experts review the draft questionnaire, they put forward the amendment suggestions. Make further amendments and improvement according to those suggestions and finally forms the formal questionnaire. This questionnaire is consisted of two parts: the first part is for teachers in terms of the goal of offering badminton courses, badminton, badminton teaching materials and selection of site and equipment, teaching outline implementation, teaching content, teaching staff, teaching hours, performance appraisal and extracurricular activities and so on. The second part is for students, in which it does a survey regarding mastery of badminton skills, participation of badminton in spare time and watching badminton match.

b) Collecting Rate of the Questionnaire. This survey randomly picks 10 colleges in Shanghai and hands out 150 questionnaires to teachers in P.E. department .It collects 142 questionnaires with the collecting rate of $94.67 \%$.Effective questionnaire number 140 copies, and the effective questionnaire rate is $98.59 \%$. Hands out 15 questionnaires to students with badminton classes in each colleges of the randomly picked 10 colleges, totally 150 questionnaires with 140 copies collected .The collecting rate is $93.33 \%$. Effective questionnaire number is 136 copies and the effective questionnaire rate is $97.14 \%$.

c) Validity Test of the Questionnaire. This paper adopts Delphi method as the validity test method. Hands out expert questionnaire of validity test to 5 experts and scholars and carry out 3 rounds of inquiry. First hand out 5 expert questionnaire and collects 5 copies. Effective collecting rate is $100 \%$. After making amendments according to the feedback from experts, carry out the second and third validity test. Hand out 5 questionnaires and collects 5. Effective collecting rate is $100 \%$. It shows the high index of validity.

d) Questionnaire Reliability Test .This questionnaire chooses re-test method as the reliability test, namely two weeks after the first questionnaire , 
randomly selects related personals from the teachers and students involved in the first questionnaire, does the same questionnaire again and calculates the reliability rate $\mathrm{R}=0.87$ of the second survey .It shows this questionnaire has high reliability.

e) Data statistics. Conventional data statistics using MS EXCEL 2003 and spss12.0 software for processing.

\section{SHANGHAI COLLEGES BADMINTON TEACHING PRESENT SITUATION}

\section{A. Badminton Teaching Staff}

This survey totally hands out 150 teacher questionnaires and selected 142 effective questionnaires. The age and age structure of the badminton teacher and former badminton teacher are shown in Table 1

TABLE I BADMINTON TEACHER AGE RANGE STATISTICS TABLE

\begin{tabular}{|llc|}
\hline \multicolumn{1}{|c|}{ Age } & Number & Percentage \\
\hline $10 \sim 30$ & 82 & $57.75 \%$ \\
$31 \sim 40$ & 3 & $26.06 \%$ \\
$41 \sim 50$ & 15 & $20.56 \%$ \\
$>50$ & 8 & $5.63 \%$ \\
Total & 142 & $100 \%$ \\
\hline
\end{tabular}

Among the badminton teachers in 10 Shanghai colleges participating in the survey, there are 82 teachers under 30 years old, $57.75 \%$ of the total badminton teachers. These energetic young teachers shoulders most of the badminton teaching tasks, which shows the obvious phenomenon of young teachers. There are 15 teachers who are between 41-50 years old, with the percentage of $10.56 \%$. This part of teachers have an average teaching experience of 10-15 years. Though they are older, they have high teaching ability, rich teaching experience and scientific research level. They are the main force to promote badminton in Shanghai College and grow with the development of badminton. Teachers who are above 51 years old with dropping strength and energy, but they have rich teaching experience and made great contribution to the college badminton career.

\section{B. Teacher Degree and Title Structure}

The research results of degree and professional title of badminton teachers in 10 Shanghai colleges are shown in Table 2 and Table 3.

TABLE II RESEARCH TABLE OF THE BADMINTO

\begin{tabular}{|lcc|}
\hline Degrree & Number & Percentage \\
\hline Master & 38 & 26.76 \\
Bachelor & 97 & 68.31 \\
College & 7 & $4.93 \%$ \\
& & \\
\hline
\end{tabular}

The state education commission proposed that he college teachers should have master or above degree. From what Table 2 shows that at present most badminton teachers in Shanghai ordinary colleges are bachelors, with $68.31 \%$.Badminton teachers with master degree only covers $26.76 \%$. Thus it can be seen that it still exists a big gap of the badminton teachers' degree in Shanghai colleges with what the state education commission proposed.

TABLE III RESEARCH TABLE OF THE BADMINTON TEACHER TILE STRUCTURE SURVEY TABLE

\begin{tabular}{|ccc|}
\hline Title & Number & Percentage \\
\hline Assistant & 38 & $26.76 \%$ \\
Lecturer & 75 & $52.82 \%$ \\
Associate professor & 18 & $12.68 \%$ \\
Professor & 11 & $7.74 \%$ \\
& & \\
\hline
\end{tabular}

From Table 3 it can be seen that the majority are lecturers in badminton teacher title structure, with a percentage of 52.82. Associate professor and above account for $10.42 \%$, assistant for $26.76 \%$. The result indicates that the rate of badminton teachers with senior title is not high in Shanghai College. The main reason is the badminton teachers are young. Meanwhile, it makes high request to young teachers: constantly improving their quality cultivation and profession competence, paying attention to the training methods such as self continuing education and on-the-job learning as well as constantly strengthening the professional study of badminton.

\section{Teacher Gender, Major Proportion}

The research result of badminton teacher gender and major proportion in 10 Shanghai colleges is shown in Table 4. The result shows that there are 39 female badminton teachers in colleges, accounts for $21.91 \%$; 57 male badminton teachers, accounts for $78.08 \%$; There are 40 teachers with badminton major, accounts for $28.77 \%$, and 102 teachers whose major is not badminton, accounts for $71.23 \%$. Percentage

TABLE IV BADMINTON TEACHER GENDER AND MAJOR PROPORTION SURVEY TABLE

\begin{tabular}{|ccc|}
\hline Title & Number & Percentage \\
\hline Female teacher & 39 & $27.63 \%$ \\
Male teacher & 103 & $72.54 \%$ \\
Badminton major & 40 & $28.17 \%$ \\
Non-badminton major & 102 & $71.83 \%$ \\
\hline
\end{tabular}

From Table 4 it's not hard to see that the difference of sex ratio of badminton teachers in Shanghai ordinary colleges is large, with $72.54 \%$ male teachers. Although teacher's gender in badminton teaching has very little influence to teaching effect, in some colleges and institutions with great gender difference, such as arts school and medical schools ,it's wise for the school to combine the actual students situation with teacher's gender when introducing badminton teacher faculty.

\section{Badminton Court and Facilities}

Through investigation, we learned that although badminton has low requirement for court, facilities and other hardware, there are still related problems of lacking of hardware such as court when colleges offering badminton teaching activities. The nonstandard hardware facilities becomes one of the main factors 
which hinder the badminton teaching being standardized and scientific .This paper does the questionnaires about the hardware facility status in 10 Shanghai colleges offering badminton teaching, collects satisfaction data of the teachers and students to badminton court and facilities .By studying the relationship between the two, it investigates the influence of the hardware facilities including court to college badminton teaching development The premise to smooth completion of college badminton teaching are adequate courts ,facilities and other hardware facilities. Although some colleges in Shanghai have built some sports fields, Table 5 shows that there are still $56.9 \%$ of the students make higher requests to badminton court. This indicates that the present college badminton facilities still cannot meet the high quality teaching requirement. As teaching necessities, shuttlecock has the feature of easy consumption and the consumption is big in teaching process. As a result, students need to purchase shuttlecock to cooperate with teaching activities. Most of the college badminton teaching is outdoor teaching. There are $64.8 \%$ of the students think weather has an impact on badminton. The badminton teaching plan is greatly influenced by weather, thus it influences badminton teaching and students' learning quality.

\section{E. Badminton Teaching Materials}

By investigated to badminton teachers authorized by10 Shanghai colleges, analyze statistically for obtained teaching outline, teaching plan, lesson plan and teaching material data, we get the results in Table 6 . The survey shows that there are 9 colleges have badminton teaching plan and 10 colleges have teaching outline among the 10 colleges participated in the survey .8 colleges have lesson plan , accounts for $80 \%$ of all the colleges. In these colleges, the proportion of the teaching materials is obviously small, with only $50 \%$.Multimedia teaching software and other teaching materials are not involved in those 5 colleges with badminton teaching materials, but only with the simple graphic materials. Besides, we also found in the survey that in colleges with teaching plan and lesson plan that it exists the individual phenomenon of coping with inspection. But in those colleges without teaching plan and lesson plan, the teaching is random and the teaching content is arranged at teacher's wish.

\section{F. Badminton Class Start Time and Teaching Hours}

This paper does related investigation and research regarding the badminton teaching hours (including semesters and hours) in Shanghai colleges. The results are shown in Table 7.

The survey shows that the badminton class start time in Shanghai colleges is not consistent. Most colleges start badminton class in the first and second year, namely 1-4 semester. Junior colleges generally start badminton class in 2-3 semester. We find in the survey that there are 10-13 hours for one semester in 10 colleges, accounts for $64.52 \%$. Just take one semester to calculate, the badminton teaching hours in Shanghai colleges are obviously more than junior colleges, more than 4 hours at an average. The practice part is 13.25 teaching hours. The theoretical part is with an average of 1.32 hours. The exam is with an average of 2.13 hours.

\section{G. Teaching Status of Main Teaching Content}

The practice part and theoretical part are the main components of the present badminton teaching in ordinary colleges. The practice part is consisted of main teaching content and auxiliary teaching content. The main teaching content regarding practice part is shown in Table 8.

From Table 8 it can be seen that $21.2 \%$ of the teachers think badminton practice teaching is too professional, $22.5 \%$ of the teachers think it has low interest and $31.2 \%$ of the teachers think the content is boring. Most students participate in badminton is not to improve the competitive level. More attention is paid on the entertainment and the impact on health.

\section{H. Badminton Exam Content and Method in Shanghai Ordinary Colleges}

The survey results of badminton exam content and method in Shanghai colleges are shown in Table 9.

From Table 9 we can see that referring to the traditional single badminton assessment method, only $16.6 \%$ of the teachers think the traditional badminton assessment is reasonable, $34.7 \%$ of the teachers think it relatively reasonable and $37.5 \%$ of the teachers think nonreasonable factors exist in it.

During the interview and investigation of badminton teachers and responsible person of the P.E department in 10 Shanghai colleges, we find almost all the badminton practice teaching content in colleges are the following 8 parts: footwork, forehand \&backhand grip, forehand clear, forehand and backhand low strike, smash, single match, introducing forehand backhand chop as well as mixed doubles tactics and match. The education and cultivation of other parts are neglected, thus bringing some negative phenomenon.

\section{BADMINTON TEACHING DEVELOPMENT COUNTERMEASURE RESEARCH IN SHANGHAI COLLEGES}

The development of badminton teaching is in urgent need of badminton teaching reform. The badminton reform should be combined with the need of college students' comprehensive development and be guided by improving college students' comprehensive quality.

\section{A. Improving the Recognition of School Leaders for Badminton}

The students' physique state not only directly determines if they can study and consolidate what they study with abundant energy, but has significant influence to adapting themselves to the intense work and new change of life in future society. As a result, improving students' physique state is of great importance. 


\section{B. Improving Teacher's Comprehensive Quality and Make Full Use of Their Leading Role}

One of the teaching organization core is teacher. Badminton teachers determine the success of badminton teaching reform. If teacher's quality fails to meet the requirement, it will hinder the teaching reform. Therefore, improving badminton teacher's comprehensive quality and change their traditional teaching concept, can we improve comprehensive education quality. It can be carried out from the following major aspects.

\section{1) Changing Teacher's Teaching Concept}

In college badminton teaching process, we should pay attention to playing two aspects, namely teacher's "teaching" and students "learning". Whether the students can give full play to their role in teaching process lies in whether the teachers can play a leading role. Teaching and learning are both premises and independent. Students' main role and teachers' leading are both dispensable.

\section{2) Constructing High-level Teachers Team}

Improving teacher's teaching skills and education background is one of the most effective ways. In order to developing college badminton, we must encourage and support teachers' professional knowledge and skill training. Badminton professional education should take young teachers as main body, forming teachers' education and training system to carry on step by step as planned. In terms of improving badminton teachers' education background, the emphasis should be placed on cultivating teacher's practice teaching ability and innovation ability.

\section{Optimizing Curriculum Structure}

The traditional sports teaching mode is the passive teaching of "teachers talk and students listen; teachers teach and students do". While as one of the basic education course, college P.E. should comply with the deepening of college curriculum reform and progress of the times, change the traditional P.E concept, update teaching mode and carry on the innovation and reform. The core of reform is students learning as main body and teachers teaching as leading factor.

\section{Selecting Proper Teaching Method}

Teaching and learning are both premises and independent. Learning need teaching and teaching is for learning. Quality education promotes the subjectivity of students, emphasizing arousing the initiative of both teaching and learning. Considering most students never played badminton in the past, it requires the teachers to fully play the function of teachers leading role and students main body, eliminating students' fear and cultivating students' interest with badminton.

\section{REFERENCES}

[1] Wang Hongjun. Liaoning Province Ordinary College Badminton Teaching Present Situation and Development Countermeasures Research [D]. Northeast Normal University, 2006.

[2] Zhou Yu. Hunan Province College Badminton Teaching Present Situation and Development Countermeasures Research [D]. Hunan Normal University, 2011.

[3] Wang Lining. Changchun Ordinary College Badminton Teaching Present Situation and Development Countermeasures Research [D]. Northeast Normal University, 2009.

[4] Chai Chengjun. College Badminton Teaching Present Situation and Development Countermeasures Research [D]. Shanghai University of Sport, 2014.

[5] Wang Hai,Huang E. College Badminton Teaching Present Situation and Development Countermeasures Research [J].Sports,2013(1):12-13.

[6] Fan Fei. College Badminton Teaching Present Situation and Development Countermeasures Research [J]. Science \& Technology Information, 2014(6):25-28 